\title{
PENGARUH PELATIHAN, PENEMPATAN DAN KINERJA KELOMPOK PAKAR SECARA PARSIAL DAN SECARA SIMULTAN TERHADAP CAPACITY BUILDING DPRD OGAN KOMERING ILIR
}

\author{
Yuliana \\ Staff ahli Sekratariat DPRD Ogan Komering Ilir \\ Email : yuliana@gmail.com \\ Fakhry Zamzam \\ Program Magister Universitas IGM Palembang \\ Email: fakhry@uigm.ac.id \\ Luis Marnisah \\ Program Magister Universitas IGM Palembang \\ Email: luismarnisah@uigm.ac.id \\ DOI: http://dx.doi.org/10.35908/jeg.v5i1.952
}

\begin{abstract}
The purpose of the research is specifically to obtain the results of the analysis of the influence of training variables, placement, expert group performance on the capacity building of DPRD partially or simultaneously. The research method uses descriptive and verification surveys, field data collection using questionnaire, interview and documentation techniques. This research is associative research, where in this study there are variables that are related and can affect other variables. The study population was 85 employees at the OKI DPRD Secretariat, taken as a sample of 71 employees. Processing data using SPSS 23 analysis tools. Testing the data using the $t$ test, that training affects capacity building with $t$ count 5.009> $t$ table 1.993, there is an influence of placement on capacity building, with 3,883> t table 1,993, performance affects capacity building with $t$ count of 2,149> $t$ table 1,993 and training, placement and performance affect capacity building with $F$ count 10,980> F table 2,683. The red thread of research is that Expert Group Training, Expert group Placement, Expert group performance has a positive and significant effect on the capacity building of Ogan Komering Ilir District DPRD both partially and simultaneously. Strategies to increase DPRD capacity building can be done by providing training before expert group placements on DPRD equipment.
\end{abstract}

Keywords: training, placement, performance and capacity building

\begin{abstract}
ABSTRAK
Tujuan penelitian secara khusus untuk mendapatkan hasil analisis pengaruh variable pelatihan, penempatan, kinerja kelompok pakar terhadap capacity building DPRD secara parsial ataupun secara simultan. Metode penelitian menggunakan survey deskriptif dan verifikatif, pengumpulan data lapangan menggunakan teknik kuesioner, wawancara dan dokumentasi. Penelitian ini merupakan penelitian assosiatif, di mana dalam penelitian ini terdapat variabel yang berhubungan dan dapat mempengaruhi variabel lain. Populasi penelitian ini adalah 85 pegawai pada Sekretariat DPRD Kabupaten OKI, diambil menjadi sampel sebanyak 71 pegawai. Pengolahan data menggunakan tools analisis SPSS 23. Pengujian data menggunakan uji t, bahwa pelatihan berpengaruh terhadap capacity building dengan t hitung 5.009> t table 1,993, terdapat pengaruh penempatan terhadap capacity building, dengan sebesar 3.883> t table 1,993, kinerja memengaruhi terhadap capacity building dengan t hitung sebesar $2.149>\mathrm{t}$ table 1,993 dan pelatihan, penempatan dan kinerja memengaruhi capacity building dengan $\mathrm{F}$ hitung 10,980 > F table 2.683. Benang merah penelitian bahwa Pelatihan Kelompok Pakar, Penempatan kelompok pakar, Kinerja kelompok pakar berpengaruh positif dan sinifikan terhadap capacity
\end{abstract}


building DPRD Kabupaten Ogan Komering Ilir baik secara parsial maupun simultan, Strategi untuk meningkatkan capacity building DPRD dapat dilakukan dengan memberikan pelatihan terlebih dahulu sebelum penempatan kelompok pakar pada alat kelengkapan DPRD.

Kata Kunci ; pelatihan, penempatan, kinerja dan capacity building

\section{PENDAHULUAN}

DPRD dalam menjalankan fungsi Legislasi, Anggaran dan pengawasan; mendapatkan dukungan dari tenaga ahli atau kelompok pakar. Kelompok pakar diangkat oleh Sekretaris DPRD atas usul DPRD. ditempatkan pada setiap alat kelengkapan DPRD berdasarkan atas usulan alat kelengkapan DPRD.Kelompok pakar secara administratif berkedudukan di bawah Sekretariat DPRD akan tetapi dalam operasionalisasinya berada di bawah kordinasi pimpinan alat kelengkapan DPRDyang bersangkutan.

$$
\text { Berkaitan dengan eksistensi }
$$

kelompok pakar DPRD, terdapat beberapa penomena penelitian yang selalu menarik menjadi diskursus seperti; kelompok pakar dalam menjalankan tugasnya cenderung kurang terkordinasi dengan Sekretariat DPRD, kelompok pakar lebih loyal kepada pimpinan alat kelengkapan DPRD daripada Sekretariat DPRD, pelaksanaan tugas kelompok pakar belum memiliki uraian tugas yang jelas, kelompok pakar belum memahami tugas dan tanggung jawabnya, rekrutmen kelompok pakar oleh DPRD cenderung lebih kental menggunakan pendekatan politis, penempatan kelompok pakar dirasakan kurang memperhatikan kompetensinya, perilaku kelompok pakar DPRD cenderung berorientasi kepada kepentingan politik, kemampuan manajerial kelompok pakar dirasakan belum diberikan secara optimal, kinerja kelompok pakar belum optimal yang berdampak terhadap rendahnya kapasitas. kelompok pakar DPRD belum pernah diberikan pelatihan orientasi tugas, rendahnya kapasitas kelompok pakar DPRD akan berdampak terhadap implementasi fungsi DPRD.Kelompok pakar DPRD sebelum ditempatkan penugasan pada alat kelengkapan DPRD belum diberikan pelatihan teknis, akan dapat berdampak terhadap capacity building.

Berbagai persoalan mengenai capacity building kelompok pakar DPRD di atas, menjadi sangat menarik untuk dikaji secara lebih mendalam melalui kajian bidang ilmu manajemen sumber daya manusia yang diperkaya dengan ilmu administrasi negara; karena persoalan capacity buildingkelompok pakar DPRD berhubungan dengan pelaksanaan fungsifungsi DPRD, ini dalam rangka pengkuatan pemerintahan di daerah untukmembangun kesetaraan yang harmonis antara eksekutif dan legislatif secara lebih optimal,

\section{RUMUSAN MASALAH}

Dari hasil identifikasi masalah capacity building di atas, maka persoalan capacity building kelompok pakar DPRD yang akan dikaji dari variabel pelatihan, penempatan dan kinerja kelompok pakar.Berkaitan implementasi fungsifungsi Dewan Perwakilan Rakyat Daerah Kabupaten Ogan Komering Ilir yang dirumuskan sebagai berikut; Bagaimanakah Pengaruh pelatihan, penempatan dan kinerja kelompok pakar secara parsial dan secara simultan terhadap capacity building DPRD? 


\section{TUJUAN PENELITIAN}

(1) Untuk mengetahui hasil analisis pengaruh pelatihan, penempatan dan kinerja kelompok pakar secara parsial terhadap capacity buildingDPRD,

(2) Untuk mengetahui hasil analisis pengaruh pelatihan, penempatan dan kinerja kelompok pakar terhadap capacity building DPRD

\section{DESAIN PENELITIAN}

Penelitian tesis ini menggunakan metode survey konfirmatif bersifat deskriptif dan verifikatif. Dimana penelitian verifikatif dilakukan untuk menguji hipotesis, sedangkan deskriptif untuk menggambarkan kondisi variabel yang diteliti. Mengunakan teknik survey deskriptif dan survey verifikatif melalui pengumpulan data di lapangan dan informasi langsung dari sampel, bila kita melihat dari ekspalanasinya, penelitian ini merupakan penelitian assosiatif, dimana dalam penelitian ini terdapat variabel yang berhubungan dan dapat memengaruhi variabel lain. (Sekaran, 2003)Menurut Kerlinger dalam Sugiyono (2012) bahwa penelitian survey adalah penelitian yang dilakukan pada populasi besar maupun kecil, tetapi data yang dipelajari adalah dari data sampel yang diambil dari populasi tersebut, sehingga ditemukan kejadian-kejadian relatif distributif dan hubungan antar variabel sosiologis maupun psikologis. Penelitian survey pada umumnya dilakukan untuk mengambil suatu generalisasi dari pengamatan yang tidak mendalam.Namun generalisasi yang dilakukan bisa lebih akurat bila digunakan sampel yang representatif (David Kline dalam Sugiyono 2012).

\section{POPULASI DAN SAMPEL}

Populasi adalah wilayah generalisasi yang terdiri atas objek/subjek yang mempunyai kualitas dan karateristik tertentu yang ditetapkan oleh peneliti untuk dipelajari dan kemudian untuk ditarik kesimpulan. (Sugiyono 2012). Disini yang akan menjadi populasi penelitian adalah seluruh pegawai pada Sekretariat DPRD Kabupaten Ogan Komering Ilir. Populasi penelitian ini adalah seluruh pegawai pada Sekretariat DPRD Kabupaten Ogan Komerig Ilir berjumlah 85 Orang.

Adapun pengukuran sampel mengacu dengan Konsep Krejcie Dan Morgan yang telah diformat dalam bentuk tabel Krejcie-Morgan sangat sederhana dan mudah digunakan, sebab secara fungsional hanya terdiri dari dua kolom penting yaitu kolom untuk ukuran populasi (N) dan kolom untuk ukuran sampel (n). Jumlah pegawai Sekretariat DPRD Kabupaten OKI sebanyak 85 orang menjadi populasi, yang akan diambil adalah sebagai sampel sebanyak 71 .

\section{TEKNIK PENGUMPULAN DATA}

Metode pengumpulan data yang digunakan dalam penelitian ini adalah sebagai berikut :

Pertama, Teknik Kuesioner, Yaitu dengan membuat instrumen penelitian dan menyebarkan kuesioner berupa daftar pernyataan, untuk memperoleh data primer secara langsung dari subjek penelitian. Kuesioner yang digunakan dalam penelitian ini merupakan angket langsung, yaitu kuesioner yang secara langsung diisi oleh responden. Kedua, Teknik Wawancara, yaitu melakukan kegiatan memberikan pertanyaan secara lisan kepada responden atau nara sumber yang 
berkompeten pada bidang yang diteliti, untuk mendapatkan data sekunder. Sebelumnya disiapkan dapat terlebih dahulu questioners guide sebagai arah bagi peneliti dalam mengajukan pertanyaan yang akan disampaikan. Penentuan responden yang dipilih dilakukan melalui pendekatan Purposive sampling dengan tujuan agar responden terpilih sesuai dengan kriteria yang sejalan dengan kebutuhan data dan informasi.

Ketiga, Teknik Dokumentasi.

Dalam Teknik dokumentasi dilakukan dengan melakukan telaahan terhadap dokumen seperti peraturan per-undangundangan yang berhubungan dengan penelitian, data sekunder tentang tenaga ahli DPRD. Keempat, Teknik Observasi Partisipan. Menurut Juanda (2009), observasi adalah salah satu instrument pengumpulan data dengan cara pengamatan dan pencatatan secara teliti dan sistematik mengenai gejala-gejala yang sedang diteliti. Dalam penelitian ini, peneliti terlibat langsung di dalamnya, sehingga menggunakan teknik observasi partisipan.

\section{VARIABEL PENELITIAN}

\section{Variabel Pelatihan}

Pelatihan dalam penelitian ini didefinisikan adalahsalah satu usaha dalam meningkatkan mutu sumber daya manusia dalam dunia kerja. Karyawan, baik yang baru ataupun yang sudah bekerja perlu mengikuti pelatihan karena adanya tuntutan pekerjaan yang dapat berubah akibat perubahan lingkungan kerja, strategi, dan lain sebagainya. Sedangkan secara operasional variabel pelatihan merupakan konstruk latent sehingga untuk operasionalisasinya perlu dijelaskan oleh beberapa indikator variabel. Indikator yang akan digunakan untuk mengukur variabel pelatihan yaitu; (1) jenis pelatihan, (2) tujuan pelatihan, (3) materi pelatihan, (4) metode pelatihan, dan (5) waktu pelatihan.

2. Variabel Penempatan

Definisi konsepsual penempatan dalam penelitian ini adalah suatu proses yang sangat menentukan dalam mendapatkan karyawan yang kompeten yang dibutukan perusahaan, karena penempatan yang tepat dalam posisi jabatan yang tepat akan dapat membantu perusahaan dalam mencapai tujuan. Sedangkan secara operasional Variabel Penempatan dalam penelitian ini merupakan konstruk latent menggunakan fist order, sehingga untuk operasionalisasinya perlu dijelaskan oleh beberapa indikator variabel. Indikator variabel penempatan kerja meliputi; (1) Pendidikan, (2) pengetahuan,

Ketrampilan, dan (4) Pengalaman.

\section{Variabel Kinerja}

Sintesis variabel kinerja dalam penelitian ini diambil dari beberapa pendapat para pakar yang akan dijadikan definisi konsepsual dalam penelitian ini, kinerja adalah tingkat kemampuan seseorang dalam pencapaian pelaksanaan tugas, yang merupakan kombinasi antara kapasitas dan upaya seseorang sesuai dengan tanggung jawab dan wewenangnya dengan pencapaian hasil pelaksanaan tugas tertentu dalam rangka mewujudkan pencapaian tujuan organisasi, Sedangkan secara Operasionalisasi kinerja terdiri dari 6 indikator adalah Quality, Quantity, timeliness, Cost effectiveness, Need for supervision dan Interpersonal impact. 


\section{Variabel Capacity Building}

Definisi operasional capacity bulding dalam penelitian ini adalah upaya yang dimaksudkan untuk mengembangkan suatu ragam strategi meningkatkan efisiensi, efektivitas dan responsivitas kinerja pemerintah. Yakni efisiensi, dalam hal waktu (time) dan sumber daya (resources) yang dibutuhkan guna mencapai suatu outcomes; efekfivitas berupa kepantasan usaha yang dilakukan demi hasil yang diinginkan; dan responsivitas merujuk kepada bagaimana mensikronkan antara kebutuhan dan kemampuan untuk maksud tersebut.

\section{RANCANGAN ANALISIS DATA}

Penelitian ini menggunakan teknik analisis data kuantitatifberupa analisis

\section{KERANGKA PEMIKIRAN TEORITIS}

Berangkat dari kerangka pemikiran teoritis, maka dapat digambarkan alur pikir penelitian sebagaimana tergambar dalam bagan alir pikir berikut;

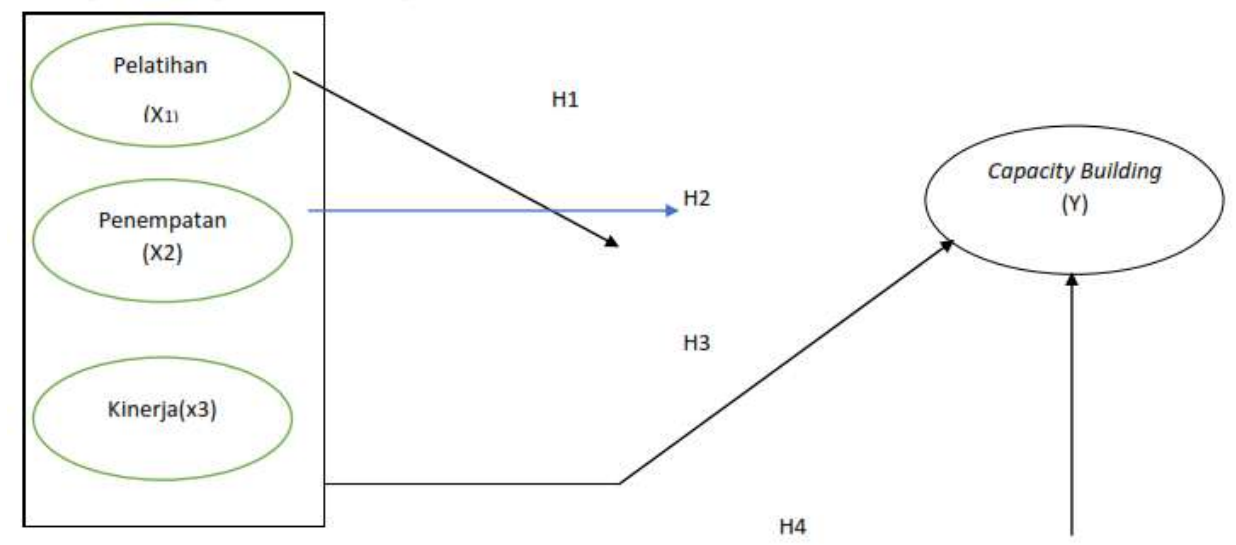

Bagan 2.1 Alur Fikir Penelitian statistika deskriptif dan analisis statistika inferensial, yakni sebagai berikut:

a. Statistika deskriptif adalah statistik yang digunakan untuk menganalisis data dengan cara mendiskripsikan atau menggambarkan data yang telah terkumpul sebagaimana adanya tanpa bermaksud mengambil kesimpulan yang berlaku untuk umum atau generalisasi (Sugiyono,2012).

b. Statistika inferensial (sering juga disebut statistik induktif atau statistik probabilitas) adalah teknis statistik yang digunakan untuk menganalisis data sampel dan hasilnya diberlakukan untuk populasi(Sugiyono, 2012)
H1 : Diduga Terdapat Pengaruh Pelatihan Kelompok Pakar Terhadap Capacity Building DPRD.

H2 : Diduga Terdapat Pengaruh Penempatan Kelompok Pakar 
Terhadap Capacity Building DPRD.

H3 : Diduga Terdapat Pengaruh Kinerja Kelompok Pakar Terhadap Capacity Building DPRD.

H4 : Diduga Terdapat Pengaruh Pelatihan, Penempatan dan Kinerja kelompok Pakar secara bersamasama Terhadap Capacity Buiding DPRD.

Analisis dan Pembahasan

Hiptesis-1

Ho : Tidak terdapat pengaruh pelatihan terhadap capacity building

H1 : Terdapat pengaruh pelatihan terhadap capacity building.

Dari hasil pengolahan data menggunakan SPSS, dan pengujian data menggunakan uji t bahwa t hitung sebesar 5.009> dengan t tabel 1.993 dan tingkat signifikansi 0,00<0,05, maka hipotesis Ho ditolak dan $\mathrm{H} 1$ diterima maka hasil pengujian hipotesis bahwa terdapat pengaruh positif dan signifikan pelatihan terhadap capacity building, sebagaimana dalam tabel berikut.

Tabel 1

Pengaruh Pelatihan Terhadap Capacity Building

\begin{tabular}{|c|c|c|c|c|c|}
\hline \multirow{2}{*}{ Model } & \multicolumn{2}{|c|}{$\begin{array}{c}\text { Unstandardized } \\
\text { Coefficients }\end{array}$} & $\begin{array}{c}\text { Standardized } \\
\text { Coefficients }\end{array}$ & \multirow{2}{*}{$\mathrm{t}$} & \multirow{2}{*}{ Sig. } \\
\cline { 2 - 6 } & $\mathrm{B}$ & $\begin{array}{c}\text { Std. } \\
\text { Error }\end{array}$ & Beta & & \\
\hline Pelatihan & 0.620 & 0.122 & 0.523 & 5.099 & 0.000 \\
\hline
\end{tabular}

Sumber : Output SPSS Diolah'2018

Dari tabel di atas diketahui bahwa tingkat signifikansi pengaruh pelatihan terhadap capacity building adalah $0,00<0,05$ dan thitung 5,099>t tabel, maka penelitian ini berhasil mengkonfirmasi teori penelitian pengaruh pelatihan terhadap capacity buildingdapat dibuktikan Hipotesis-2

Ho : Tidak terdapat pengaruh penempatan terhadap capacity building
H1 : Terdapat pengaruh penempatan terhadap capacity building

Hasil pengolahan data menggunakan SPSS, dengan menggunakan uji t bahwa thitung sebesar 3.883> dengan $\mathrm{t}$ tabel 1,993 dan tingkat signifikansi $0,00<0,05$, maka hipotesis bahwa Ho ditolak dan $\mathrm{H} 1$ diterima maka hasil pengujian hipotesis membuktikan terdapat pengaruh penempatan terhadap capacity building.

Tabel 2

Pengaruh Penempatan Terhadap Capacity Building

\begin{tabular}{|c|c|c|c|c|c|}
\hline \multirow{2}{*}{ Model } & \multicolumn{2}{|c|}{$\begin{array}{c}\text { Unstandardized } \\
\text { Coefficients }\end{array}$} & $\begin{array}{c}\text { Stand } \\
\text { ardize } \\
\mathrm{d} \\
\text { Coeffi } \\
\text { cients }\end{array}$ & $\mathrm{T}$ & Sig. \\
\cline { 2 - 4 } & $\mathrm{B}$ & $\begin{array}{c}\text { Std. } \\
\text { Error }\end{array}$ & Beta & & \\
\hline $\begin{array}{c}\text { Penempa } \\
\text { tan }\end{array}$ & 0.651 & 0.170 & 0.419 & 3.833 & 0.000 \\
\hline
\end{tabular}

Sumber : Output SPSS Diolah'2018

Hiptesis-3

Ho : Tidak terdapat pengaruh kinerja terhadap capacity building

H1 : Terdapat pengaruh kinerja terhadap capacity building

Dari hasil pengolahan data menggunakan SPSS, dengan menggunakan uji t bahwa thitung sebesar 2.149> dengan t tabel 1,993 dan tingkat signifikansi 0,035 $<0,05$, maka hasil uji hipotesis bahwa Ho ditolak dan H1 diterima, maka hasil pengujian hipotesis membuktikan terdapat pengaruh kinerja terhadap capacity building, sebagaimana tersebut dalam tabel berikut ini.

Tabel 3

Pengaruh Kinerja Terhadap Capacity

Building

\begin{tabular}{|c|c|c|c|c|}
\hline Model & $\begin{array}{c}\text { Unstandardize } \\
\text { d Coefficients }\end{array}$ & $\begin{array}{c}\text { Standar } \\
\text { dized }\end{array}$ & $\mathrm{T}$ & Sig. \\
\hline
\end{tabular}




\begin{tabular}{|c|c|c|c|c|c|}
\hline & & & \multirow{2}{*}{$\begin{array}{c}\text { Coeffic } \\
\text { ients }\end{array}$} & & \\
\hline & B & $\begin{array}{l}\text { Std. } \\
\text { Error }\end{array}$ & & & \\
\hline Kinerja & 0.244 & 0.113 & 0.250 & 2.149 & 0.035 \\
\hline
\end{tabular}

Sumber : Output SPSS Diolah'2018

Dari tabel di atas, bahwa kinerja berpengaruh secara positif dan signifikan terhadap capacitu buildingdengan tingkat signifikansi $0,035<0,05$.

Hiptesis-4

Ho : Tidak terdapat pelatihan, penempatan dan kompetensi pengaruh terhadap capacity building

H1 : Terdapat pengaruh pelatihan, penempatan dan kinerja terhadap capacity building

Pelatihan, penempatan dan kinerja berpengaruh secara bersama-sama terhadap capacity building. Hasil pengolahan data menggunakan SPSS, dengan menggunakan uji $\mathrm{F}$ bahwa $\mathrm{F}$ hitung sebesar 10,980> dengan Ftabel 2,683 dan tingkat signifikansi $0,00<0,05$, maka hipotesis bahwa Ho ditolak dan H1 diterima,dengan demikian hasil pengujian hipotesis dapat mengkonfirmasi terdapat pelatihan, penempatan, dan kinerja berpengaruh terhadap capacity bulding sebagaimana tergambar dalam tabel berikut ini

\section{Tabel 4}

Pengaruh Pelatihan, Penempatan dan

Kinerja secara Bersama-sama terhadap Capacity Building.

\begin{tabular}{|c|c|c|c|c|c|}
\hline Model & $\begin{array}{c}\text { Sum of } \\
\text { Squares }\end{array}$ & df & $\begin{array}{c}\text { Mean } \\
\text { Square }\end{array}$ & F & Sig. \\
\hline Regression & 469.588 & 3 & 156.529 & 10.980 & $.000^{\mathrm{b}}$ \\
\hline
\end{tabular}

Sumber : Output SPSS Diolah'2018

Dengan demikian maka hasil uji hipotesis-4 dapat mengkonfirmasi teori bahwa terdapat pengaruh pelatihan, penempatan dan kinerja secara bersamasama terhadap capacity building

\section{ANALISIS DAN PEMBAHASAN}

\section{Analisis Pengaruh Pelatihan}

\section{Kelompok Pakar Terhadap}

Capacity Building DPRD.

Pelatihan kepada kelompok pakar DPRD menjadi penting, di mana akan memberikan pengaruh terhadap capacity building DPRD. Besaran pengaruh pelatihan kelompok pakar terhadap capacity building sebesar 0,274 atau $27,4 \%$ sebagaimana tergambar dalam tabel di bawah ini.

Tabel . 5

Besaran Pengaruh Pelatihan Terhadap CapacityBuilding

\begin{tabular}{c|c|c|c|c|}
\hline Model & $\mathrm{R}$ & R Square & $\begin{array}{c}\text { Adjusted } \\
\text { R Square }\end{array}$ & $\begin{array}{c}\text { Std. Error } \\
\text { of the } \\
\text { Estimate }\end{array}$ \\
\hline 1 & $0.523^{\mathrm{a}}$ & 0.274 & 0.263 & 3.87268 \\
\hline
\end{tabular}
Sumber : Output SPSS Diolah'2018
Indikator

tertinggi dalam menjelaskan capacity buildingadalah PL.02 yaitu pelatihan kelompok pakar DPRD untuk peningkatan kompetensi dengan koefisien 3,7887. Karena setelah calon kelompok pakar yang telah lulus seleksi, sejatinya diberikan pelatihan teknis terlebih dahulu tentang alat kelengkapan DPRD, administrasi dan manajerial.

Menurut Mathis dan Jackson (2004) pelatihan dapat dirancang untuk memenuhi tujuan berbeda dan dapat diklasifikasikan ke dalam berbagai cara, yang meliputi:

1. Pelatihan yang dibutuhkan dan rutin: dilakukan untuk memenuhi berbagai syarat hukum yang diharuskan dan berlaku sebagai pelatihan untuk semua karyawan (orientasi karyawan baru). 
2. Pelatihan pekerjaan/teknis: memungkinkan para karyawan untuk melakukan pekerjaan, tugas dan tanggung jawab mereka dengan baik.

3. Pelatihan antarpribadi dan pemecahan masalah: dimaksudkan untuk mengatasi masalah operasional dan antarpribadi serta meningkatkan hubungan dalam pekerjaan organisasional.

4. Pelatihan perkembangan dan inovatif : menyediakan fokus jangka panjang untuk meningkatkan kapabilitas individual dan organisasional untuk masa depan.

\section{Analisis Pengaruh Penempatan Kelompok Pakar Terhadap Capacity Building DPRD}

Penempatan kelompok sesuai dengan latar belakang Pendidikan, pengalaman kerja dam kompetensi akan berpengaruh terhadap capacity building. Pendapat di atas telah sesuai dengan hasil penelitian, sehingga penelitian ini dapat mebuktikan bahwa teori telah sesuai dengan empiris di lapangan. Koefisien regresi penempatan klompok pakar berpengaruh terhadap capacity building sebesar 0,176 atau mencapai 17,6\%. Hal sesuai dengan hasil pengolahan data dengan menggunakan SPSS 23 sebagaimana digabarkan secara jelas dalam tabel berikut ini

Tabel 6

Pengaruh Penempatan -Capacity Building

\begin{tabular}{|c|c|c|c|c|}
\hline Model & $\mathrm{R}$ & R Square & $\begin{array}{c}\text { Adjusted R } \\
\text { Square }\end{array}$ & $\begin{array}{c}\text { Std. Error of the } \\
\text { Estimate }\end{array}$ \\
\hline 1 & $0.419^{\mathrm{a}}$ & 0.176 & 0.164 & 4.12591 \\
\hline
\end{tabular}

Sumber : Output SPSS Diolah'2018

Indikator variabelpenempatan yang tertinggi pengaruhnya terhadap peningkatan capacity building adalah PN.07 yaitu Penempatan kelompok pakar DPRD memperhatikan Pendidikan dengan koefisien 4,2535. Karenanya penempatan kelompok pakar memerhatikan Pendidikan, kompetensi dan pengalaman merupakan hal utama.
Dikutip
dari
Suwatno

(2003:129), dalam melakukan penempatan karyawan hendaknya mempertimbangkan hal-hal sebagai berikut:
a. Pendidikan
b. Pengetahuan kerja
c. Ketrampilan kerja
d. Pengalaman kerja

\section{Analisis Pengaruh Kinerja Kelompok Pakar Terhadap Capacity Building DPRD.}

Tentunya kinerja berhubngan dengan erat dengan capacity buiding, semakin baik kinerja akan semakin meningkat pula capacity building. Pengaruh kinerja terhadap capacity building mencapai 0,063 atau 6,3\%, sebagaimana digambaran dalam tabel di bawah ini.

Tabel 7

Pengaruh Kinerja terhadap CapacityBuilding

\begin{tabular}{|c|c|c|c|c|}
\hline Model & $\mathrm{R}$ & $\begin{array}{c}\mathrm{R} \\
\text { Square }\end{array}$ & $\begin{array}{c}\text { Adjusted } \\
\text { R Square }\end{array}$ & $\begin{array}{c}\text { Std. Error of } \\
\text { the Estimate }\end{array}$ \\
\hline 1 & $0.250^{\mathrm{a}}$ & 0.063 & 0.049 & 4.39921 \\
\hline
\end{tabular}

Sumber : output SPSS Diolah'2018

Indikator variable kinerja yang tertinggi pengarhnya terhadap peningkatan capacity building adalah KJ.11 yaitu Kelompok pakar DPRD saling dukung dalam tugas dengan koefisein 3,9155. Kerjasama antar kelompok pakar ini menjadi kunci utama untuk meningkatkan peran kelompok pakar, pada gilirannya dapat mendorong terhadap peningkatan capacity building DPRD

Menurut Dale (1992), bahwa kinerja seseorang tergantung pada kombinasi dari kemampuan, usaha dan kesempatan yang diperoleh. Lingkungan 
kerja yang menyenangkan mungkin menjadi kunci pendorong bagi karyawan untuk menghasilkan kinerja puncak. Pada dasarnya kinerja dari seseorang merupakan hal yang bersifat individu karena masingmasing dari karyawan rnempunyai tingkat kemampuan yang berbeda. Kinerja seseorang tergantung pada kombinasi dari kemampuan, usaha dan kesempatan yang diperoleh. Lingkungan kerja yang menyenangkan mungkin menjadi kunci pendorong bagi karyawan untuk menghasilkan kinerja puncak(Dale, 1992). Robbins (1996), menyatakan kinerja sebagai fungsi interaksi antara kemampuan atau ability. (A), Motivasi atau Motivation. (M) dan kesempatan atau opportunity.(O), yaitu dirumuskan sebagai berikut :

\section{Kinerja $=\mathbf{f}(\mathrm{A}, \mathrm{M}, \mathrm{O})$}

Artinya, kinerja merupakan fungsi dari kemampuan, motivasi, dan kesempatan.

Dengan demikian, kinerja ditentukan oleh faktor-faktor tersebut. Ambar (2000), menyatakan bahwa kesempatan pengembangan karier yang adil dan transparan dan kepemilikan kemampuan teknis dapat meningkatkan kinerja karyawan.

\section{Analisis Pengaruh Pelatihan, Penempatan dan Kinerja Kelompok Pakar Terhadap Capacity Building DPRD}

Secara simultan pelatihan, penempatan dan kompetensi kelompok pakar secara Bersama-sama memengaruhi capacity building. Secara Bersama-sama pengaruh ketiga variabel tersebut adalah mencapai 0,30 atau $30 \%$, sehngga 52,6\% dapat dipengaruhi oleh variasi variabel lain. Pengaruh ketiga variabel tersebut dijelaskan dalam tabel di bawah ini.

\section{Tabel 8}

Besaran Pengaruh Pelatihan, Penempatan

Dan Kinerja Secara Bersama-Sama Terhadap Capacity Building

\begin{tabular}{|c|c|c|c|c|}
\hline Model & $\mathrm{R}$ & R Square & $\begin{array}{c}\text { Adjusted } \\
\text { R Square }\end{array}$ & $\begin{array}{c}\text { Std. Error of } \\
\text { the Estimate }\end{array}$ \\
\hline 1 & $0.574^{\mathrm{a}}$ & 0.330 & 0.300 & 3.77570 \\
\hline
\end{tabular}

Sumber : Output SPSS Diolah'2018

Dari ketiga variabel tersebut di atas, yang paling dominan memengaruhi capacity building adalah variabel mencapai $27,4 \%$, disusul pengaruh variabel penempatan sebesar $17,6 \%$ dan variabel kinerja sebesar 6,3\%. Secara simultan pengaruh variabel pelatihan, penempatan dan kinerja terhadap capacity building adalah 0.33 atau $30 \%$, sehingga $70 \%$ lain dipengaruhi oleh beberapa variabel lain seperti system rekrutmen, seleksi, motivasi, kompetensi, dan kompensasi

Indikator variabel pelatihan yang tertinggi memengaruhi capacity building adalah PL.02 yaitu pelatihan kelompok pakar DPRD untuk peningkatan kompetensi dengan koefisien 3,7887, sedangkan indikator variabel penempatan tertinggi memengaruhi capacity building adalah PN.07 yaitu penempatan kelompok pakar DPRD memperhatikan Pendidikan dengan koefisien 4,2535 dan indicator variabel kinerja tertinggi memengaruhi capacity building adalah KJ.11 yaitu kelompok pakar DPRD saling dukung dalam tugas dengan koefisein 3,9155. Dalam hal ini berarti untuk meningkatkan capacity building perlu dilakukan pelatihan kepada kelompok pakar agar dapat meningkatkan kompetensi, penempatan kelompok pakar perlu memrhatikan latar belakang Pendidikan yang bersangkutan dengan tugas alat kelengkapan DPRD dimana kelompok pakar ditugaskan dan kerjasama yang saling mendukung antar 
kelompok pakar tetap dipertahankan dan jika perlu lebih ditingkatkan .

\section{SIMPULAN}

Dari hasil pengujian hipotesis dan analisis dan pembahasan pada bab sebelumnya maka dapat ditarik benang merah penelitian sebagai berikut;

1. Pemberian Pelatihan kepada Kelompok Pakar sebelum ditempatkan pada alat kelngkapan DPRD berpengaruh secara positif dan signifikan terhadap peningkatan capacity building DPRD Kabupaten Ogan Komering Ilir

2. Penempatan kelompok pakar sesuai dengan kompetensi yang bersangkutan berpengaruh secara positif dan signifikan terhadap capacity building DPRD Kabupaten Ogan Komering Ilir

3. Kinerja kelompok pakar yang baik berpengaruh secara positif dan sinifikan terhadap capacity building DPRD Kabupaten Ogan Komering Ilir

4. Pelatihan, penempatan dan kinerja kelompok pakar secara bersama-sama memengaruhi positif dan signifikan terhadap capacity building DPRD Kabupaten Ogan Komering Ilir

\section{IMPLIKASI MANAJERIAL}

Strategi untuk meningkatkan capacity building DPRD dapat dilakukan dengan memberikan pelatihan terlebih dahulu kepada kelompok pakar sebelum menugaskan kelompok pakar pada alat kelengkapan DPRD dan penempatan kelompok pakar pada alat kelengkapan DPRD agar memerhatikan kompetensi, pendidikan dan pengalaman kerja calon kelompok pakar.

SARAN TINDAK LANJUT
1. Bagi Pengembangan ilmu manajemen sumber daya manusia dapat dilakukan penelitian lanjutan dengan menambahkan beberapa variasi variabel seperti sistem seleksi, rekrutmen, kompetensi, dan kompensasi.

2. Bagi Sekretariat DPRD dapat diimplementasikan dalam rangka efektivitas manajemen Sekretariat DPRD guna peningkatan peran kelompok pakar DPRD secara efektif lagi untuk dapat meningkatkan capacity building Dewan Perwakilan Rakyat Daerah.

\section{DAFTAR PUSTAKA}

Andes Pirmansyah, 2010, Pengaruh Pendidikan dan Pelatihan (Diklat) Terhadap Pengembangan Karir Karyawan Pada Bank Pd. BPR Sarimadu Bangkinang. Thesis, Universitas Islam Negeri Sultan Syarif Kasim Riau.

Anni Milen, 2004, Pegangan Dasar Pengembangan Kapasitas. Diterjemahkan secara bebas. Yogyakarta, Pondok Pustaka Jogja.

Arikunto, Suharsimi, 2014, Prosedur Penelitian, Suatu Pendekatan Praktik, Jakarta, Penerbit PT Rineka Cipta.

Azwar, Syaifuddin, 2009. Metode

Penelitian. Yogyakarta. Pustaka Pelajar

Bahri. Samsul, Zamzam Fakhry, 2014, Model Penelitian Kuantitatif berbasis SEM Amos, Yogyakarta, Penerbit DeePublish

Bernadin, H., dan Russel, Joyce, E.A, 1993, Human Resources Management, Singapore, Mcgraw Will inc

Berry, Lilly M \& John P. Houston. 1993. Psychology At Work. USA: Brown \& Benchmark 
Billy Renaldo Potale, Viktor Lengkong, Silcyljeova Moniharapon, 2016, Pengaruh Proses Rekrutmen Dan Seleksi Terhadap Kinerja Karyawan Pada Pt Bank Sulutgo, Jurnal Berkala Ilmiah Efisiensi Volume 16 No. 04 Tahun 2016

Creech, Bill, 1996, Lima Pilar, Manajemen Mutu Terpadu, Jakarta, Penerbit BinaRupa Aksara

Dessler, Gary. 2009. Human Resource Management, 8th Edition. New Jersey: Aprentice-Hall, Inc.

Drastari, Aning. 2014. Pengaruh Penempatan dan Pelatihan Terhadap kinerja Karyawan PT. PLN (Persero) Distribusi Jawa Timur Area Malang. Tesis, Manajemen, Fakultas Ekonomi, Universitas Negeri Malang.

Ellen, Steph. eHow Blog, 2010; Principles and Methods of Research; Ariola et al. (eds.); 2006 diakses dari http://tatangmanguny.wordpress.com /2010/04/19/ukuran-sampelrumusslovin/\#more-1104 tanggal 19 April 2010

Esa Devi Safiani, 2014, Pembangunan Kapasitas (Capacity Building)Usaha Mikro, Kecil Dan Menengah (UMKM) Di Kota Bandar Lampung Dalam rangka Menghadapi Masyarakat Ekonomi Asean 2015. Pemerintah Kota Bandar Lanpung.

Firdaus, Zamzam Fakhry, 2018 Aplikasi Metodologi, Yogyakarta, Penerbit Deepublish

Gatewood, R. and Field, H. 2001, Human Resource Selection. Harcourt Brace \& Company, Orlando.

Ghozali,Imam, 2001. Aplikasi Analisis Multivariate dengan Program SPSS, Edisi 3. Semarang: Badan Penerbit Universitas Diponegoro.
Gomes, Faustino Cardoso. 2003. Manajemen Sumber Daya Manusia. Yogjakarta: Penerbit Andi Offset.

Grindle, M.S., (editor), 1997, Getting Good Government : Capacity Building in the Public Sector of Developing Countries, Boston, MA: Harvard Institute for International Development.

Handoko, T Hani, 2011, Manajemen Personalia \& Sumber Daya Manuasi, Yogyakarta, Penerbit FE Bisnis, UGM

Hasibuan, Malayu S.P. 2008. Manajemen Sumber Daya Manusia, Edisi Revisi. Jakarta,Penerbit Bumi Aksara.

Hendriani, S., Efni, Y., \& Fitriani, A. (2013). Pengaruh Pendidikan Dan Pelatihan, Kompetensi Terhadap Kinerja Karyawan PT. Bank Riau Kepri Kantor Pusat Pekanbaru. Jurnal Pendidikan Ekonomi dan Bisnis, 5(2), 133-144.

Imam Hardjanto, 2006,Pembangunan Kapasitas Lokal (Local Capacity Building), Malang, Program Pascasarjana Universitas Brawijaya.

Juanda, Bambang, 2009, Metodologi Penelitian Ekonomi dan Bisnis, Edisi Kedua, Bogor, Penerbit IPB Press

Kasim, Azhar. 1993. Pengukuran Efektivitas Organisasi. Jakarta: Fakultas Ekonomi Universitas Indonesia

Kusnendi, 2008, Model-Model Persamaan Struktural Satu dan Multigroup sampel dengan Listrel, Bandung, Penerbit Alfabeta

Mahsun, M. (2006). Pengukuran kinerja sektor publik. Yogyakarta: Penerbit BPFE.

Mathis, Robert.L. and Jackson, J.H., 2011. Human Resource Management: Essential Perspectives. Cengage Learning. 
Marnisah, Luis, 2019. Hubungan Industrial dan Kompensasi, Yogyakarta: Deepublish

Mita Widyastuti , 2010,Peningkatan Kapasitas Lembaga (Capacity Building) DPRD Kabupaten/Kota. Vol 11, No 01,

Mowday, R.T., 1996. Expectancy theory approaches to faculty motivation. New Directions for Teaching and Learning, 1982(10), pp.59-70

Mulyono, A. 2015. Pengembangan Kapasitas Aparatur Sipil Negara di Daerah. JKMP (Jurnal Kebijakan dan Manajemen Publik), 3(1), 17-34.

Rivai, Veithrizal., \& Sagala, E. J. (2013). Manajemen Sumber Daya Manusia untuk Perusahaan: Dari Teori ke Praktik Edisi Kedua.

Robbins, Stephen.F. 1996, Managing Organizational Conflict, PrenticeHall, Eaglewood Cliff, Newyork

Sebastian Rainsch, (2004), Dynamic Strategic Analysis: Demystifying Simple Success Strategies, Wiesbaden: Deutscher UniversitastsVerlag.

Sekaran, Uma, 2003, Research Methods For Bussiness, Shoutern Illinois Univercity at Carbondale

Shaputra, A. R., \& Hendriani, S. (2015). Pengaruh Kompetensi, Komitmen Dan Pengembangan Karir Terhadap Kinerja Karyawan PT. Bank Rakyat Indonesia (Persero) Kantor Wilayah Pekanbaru. Jurnal Tepak Manajemen Bisnis, 7(1), 1-17.

Simanjuntak, Payaman P. 2011. Manajemen Hubungan Industrial. Jakarta: Lembaga Penerbitan Fakultas Ekonomi UI.

Sugiyono. 2012. Metode Penelitian Kuantitatif. Bandung, Penerbit CV. Alfabeta..
Sulistiyani, Ambar T. dan Rosidah.2009., Manajemen Sumber Daya Manusia, Yogyakarta: Penerbit Graha Ilmu.

Supriyono, Bambang, dkk, 2012, Capacity Building, Malang, Penerbit Universitas Brawijaya Press.

Suwatno, Tjutju Yuniarsih, 2008, Manajemen Sumber Daya Manusia Teori, Aplikasi dan

Timpe, Dale., 2000. Kinerja, Seri Sumber Daya Manusia. Jakarta: Gramedia Tondok, Marselius Sampe. Versi online http://www. scribd. com.

Zamzam, Fakhry, Havis Aravik, 2016. Manajemen SDM Berbasis Syariah, Bogor: CV. RWTC Success

Zamzam, Fakhry, 2015, Teknik Dasar Penulisan Proposal Tesis, Palembang, Penerbit Noerfikri

Zamzam, Fakhry, 2014, Good Governance Sekretariat DPRD, Yogyakarta, Penerbit DeePublish

Zamzam, F. (2016). Sinergisme Pengaruh Pengembangan Karier Dan Iklim Organisasi Melalui Moderasi Motivasi Kerja Terhadap Implementasi Good Governance Sekretariat DPRD Dalam Wilayah Sumatera Selatan. Jurnal Ecoment Global; Kajian Bisnis dan Manajemen, 1(1), 77-92.

Zamzam, F. (2016). Pengaruh Pengembangan Karier dan Iklim Organisasi terhadap Kinerja Pegawai Sekretariat DPRD Kabupaten OKI dengan Variabel Kepuasan Kerja sebagai Intervening. Ekonomica Sharia, 1(2), 1-12. 